\title{
STUDY OF OPERATIVE OUTCOME OF CORNUAL CANNULATION IN HYSTEROLAPAROSCOPY
}

\section{Gynecology}

Minal Dhanvij*

MS Obstetrics and Gynecology, Resident at Seth . G. S. Medical College and Nowsrosjee Wadia Maternity Hospital, Mumbai * Corresponding Author

Dr. Kiran Dhurve

MS, DNB Obstetrics and Gynecology, Former Resident at Seth . G. S. Medical College and Nowsrosjee Wadia Maternity Hospital, Mumbai

Dr. Nitin Narvekar MD Obstetrics and Genaecology, Retired Professor Seth G. S. Medical College and Nowrosjee Wadia Maternity Hospital, Mumbai

\section{ABSTRACT}

Tubo-Peritoneal disease is the cause of infertility in approximately $30 \%$ of women, and $10-25 \%$ of these are due to proximal tubal obstruction. Hysterosalpngography(HSG) can diagnose the proximal tubal block but confirmation needed by hysterolaparoscopic chromopertubation before subjecting patient to expensive reproductive techniques. In our study of 48 cases, we found out the success rate of cornual cannulation by catheterguidewire system is almost $81.25 \%$ with false positive rate of HSG is $27.2 \%$ and sensitivity of $86.4 \%$. We also found out that pelvic inflammatory disease and tuberculosis contributes to $43.9 \%$ cases of proximal tubal block and success rate was approximately $50 \%$ can be achieved in this cases. Hysterolaparoscopic cornual cannulation is simple, cost effective and promising treatment for proximal tubal pathology than tubo-cornual anastomosis with minimal complications. So we conclude that it should be offer on priority basis to treat infertile patients.

\section{KEYWORDS}

Hysterosalpingography, Hysterolaparoscopy, Proximaltubal block, Cornual cannulation

\section{INTRODUCTION}

The delicate fallopian tube is anatomic pathway to human reproduction and tubal pathology leads to $30-40 \%$ of infertility cases. Tubal and peritoneal pathology is among the most common causes of infertility and it is the primary diagnosis in approximately $30-35 \%$ of both younger and older infertile women. A history of pelvic inflammatory disease (PID), tuberculosis, septic abortion, ruptured appendix, tubal surgery, or ectopic pregnancy strongly suggest the possibility of tubal damage. Globally, 50 to 80 million couples at some point in their reproductive lives suffer from infertility problems

Hystero-salpingography HSG) and laparoscopy are the two classic methods for evaluation of tubal patency in infertile women and are complimentary rather than mutually exclusive. HSG images the uterine cavity and reveals the internal architecture of tubal lumen, neither of which can be evaluated by laparoscopy. Proximal tubal occlusions represent approximately one-third of all tubal obstructions observed with HSG and should be confirmed by hysterolaparoscopy preventing from many women going for major surgery or expensive reproductive techniques.

Tubo-cornual anastomosis that is microsurgical segmental tubal resection and anastomosis is a proven treatment for true proximal tubal obstruction. In a nonrandomized retrospective analysis with 74 patients over a 10 -year period, the results in patients with normal distal tubes, intrauterine pregnancy rates were similar and ectopic pregnancy rates were lower in the cannulation group versus anastomosis. In the era of laparoscopy proximal tubal cannulation using hysterolaparosopy is proven alternative to traditional microsurgical repair with less morbidity and lower cost. The specialized catheterguidewire systems requires training and experience with small learning curve and allows selective tubal perfusion with accurate diagnosis and treatment.

Novy and associates described a technique of trans-cervical cannulation of the proximal oviduct with a 3-F Teflon catheter and flexible guidewire $0.018 \mathrm{inch}(0.043 \mathrm{~cm}$ in diameter) in hysteroscopic cannulation with direct visualization by laparoscopy or laparotomy was successful in $92 \%$ cases. ${ }^{4}$ The success of cornual cannulation is dependent upon both the nature and extent of tubal damage as well as the expertise of the surgeon.

\section{AIMS AND OBJECTIVES}

AIM- To study the operative outcome of cornual cannulation by hysteron-laparoscopy.

\section{OBJECTIVES}

\section{Primary Objective}

1. To determine the operative outcome of hystero-laparoscopy in cornual block In infertile women

2. To determine the success rate of cornual cannulation by hysterolaparoscopy

\section{Secondary Objective}

1. To determine false positive rates of cornual block reported by Hystero-salpingography (HSG).

2. To evaluate factors which are responsible for cornual block on Hystero-laparoscopy.

\section{MATERIALS AND METHODS}

This is a prospective, observational study which was conducted in the Department of Maternity care and infertility clinic attached to a teaching medical institute. The study commenced after the approval of the Institutional Ethics Committee. The duration of study was twentyfour months.

\section{METHODOLOGY}

STUDY DESIGN: - Prospective observational study

STUDY SUBJECTS: Women which on evaluation for fertility to be found having cornual block on Laparoscopy.

SAMPLING TECHNIQUE: Systematic random sampling.

\section{SAMPLE SIZE: 48}

$\mathbf{N}=4 \times \mathrm{P} \times \mathrm{Q} \times \mathrm{N} / \mathrm{e}^{2}[\mathrm{~N}-1]+4 \mathrm{PQ}$

$P$ - Occurrence of CORNUAL BLOCK CASES based on previous literature [20-25\%].

Q $\quad-100-\mathrm{P}=80$

$\mathbf{N}$ - no. of Cornual block cases in 2 years [50]

e $=10 \% \mathrm{P}=2$

$\mathbf{n}=4 \times 20 \times 80 \times 50 / 4[49]+4 \times 20 \times 80=48$.

\section{Inclusion Criteria}

1. Patients with primary Infertility and Secondary infertility undergoing hysterolaparoscpy for evaluation and treatment of cornual block that is shown on HSG

2. Patients with infertility undergoing Hysterolaparoscopy for evaluation and are found to have cornual block on chromopertubation.

\section{Exclusion criteria}

1. Women with HSG showing mid tubal block

2. Women on USG or HSG showing dense Pelvic adhesions

3. Women with severe pelvic adhesions due to tuberculosis.

4. Patients with active genital infection are excluded. 


\section{STUDY PERIOD: Twenty four months.}

STUDY PROCEDURE: After obtaining the informed consent patients were included in study based on inclusion and exclusion criteria. Patient information sheets included information explaining in a simple manner without using scientific terminology, the purpose of the study, consenting for the study, advantages and disadvantages of taking part in the study, issues related to confidentiality of data, and the people involved in the research.

Ethical clearance received from the Institutional Ethics Committee.

After correcting other factors for infertility, HSG and ultrasonography done to see the uterine and tubal factors. Patients with cornual block are posted for Hysterolaparosopy. Hysterolaparoscopy approach enable to evaluate the entire pelvis, along with the tubal cannulation, treatment of additional problems affecting the fallopian tubes, particularly adhesions and endometriosis is possible. Cornual cannulation is done with a 3-F Teflon catheter and flexible guide-wire of $0.018 \mathrm{inch}(0.043 \mathrm{~cm}$ in diameter $)$

Proximal tubal obstruction, either unilateral or bilateral, is a frequent finding on hysterosalpingogram (HSG). The distinction between true pathologic occlusion and either spasm or plugging is crucial in determining therapy. Hysteroscopic cannulation of the fallopian tube is a safe diagnostic procedure that can be used to identify those patients with true proximal occlusion, and may also serve as a therapeutic procedure using a flexible tip guidewire for patients with true cornual block.

Cornual cannulation by hysterolaparoscopy offers a number of advantages over other techniques like fluoroscopy or sonosalpingography. The guidance of tubal catheter into the tubal ostia is simple because it is done under direct vision. Moreover laparoscopy helps to monitor the procedure and offers to assess tubal patency, leading to the ability to observe the utero-tubal junctions (UTJs) directly by hysteroscopy and hence prevents tubal perforations.

\section{Classification of proximal tubal occlusion}

Intraluminal

- Debris, viscous mucous, endometriosis

- Polyps

- Parasitic infection

\section{Intramural (mucosal, muscular, or serosal)}

- Muscular spasm

- Inflammatory fibrosis

- Salpingitis isthmic nodosa

- Neoplasia polyp, tumor

- Endometriosis

- Congenital atresia

\section{Extramural}

- Leiomyoma

- Adenomyoma

- Intrauterine synichie

- Broad ligament fibroid

The relatively higher success rate of cornual cannulation depends on:

1) Accurate visualization of both ostia before passing catheter, which definitely facilitated the successful cannulation,

2) Hydrotubation

\section{Indication for Cornual Cannulation}

The American Society of Reproductive Medicine has recommended that patients in whom the hysterosalpingography demonstrates proximal tubal occlusion on HSG should undergo cornual cannulation.

\section{RESULTS}

This was a prospective, observational, study which was conducted in the Department of maternity care and infertility clinic with sample size of 48 . The duration of study was 24 months.

DEMOGRAPHIC DATA

- This data states that age of the cases was ranging from 21 to 41 years with average being 30.02 years.

- Duration of marriage was ranging from 2.00 to 12.00 years with average being 4.51 years.
PROFILE OF OBSTETRIC HISTORY and INFERTILTY

In our study, $56.2 \%(27 / 48)$ were nulligravida and $43.8 \%(21 / 48)$ of the cases was multigravida patients among that, $90.5 \%$ of the cases had abortion previously and $9.5 \%$ of the cases had previous live birth Thus, $56.2 \%$ of the cases had primary infertility and $43.8 \%$ of the cases had secondary infertility.

\section{PERIOD OF INFERTILITY AMONG STUDY CASES}

This data states that $43.8 \%$ of the cases had period of infertility $<1$ year followed by $33.3 \%$ of the cases had period of infertility $1.1-2$ years, $10.4 \%$ patients was having infertility of duration $2.1-3$ years $12.5 \%$ patients had a history of infertility of more than 3 years.

\section{PROFILE OF PID AND TUBERCULOSIS AMONG STUDY}

\section{CASES}

Among the candidates, $37.5 \%(18 / 48)$ had a history of pelvic inflammatory disease in the past and $16.6 \%(8 / 48)$ patients had the history of tuberculosis.

\section{PROFILE OF PELVIC SURGERY}

$22.9 \%(11 / 48)$ patients found to have a history of pelvic surgery for check curettage, ovarian cyst and appendectomy.

To summarise, Figure 1. Shows the percentage of different causes for cornealblock.

Causes of cornual block for Infertility
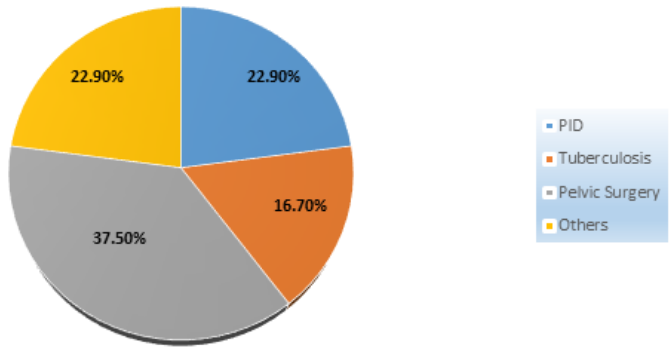

Figure 1. Pictorial representation for causes of cornual block.

CORNUAL BLOCK ON LAPAROSCOPY AND SUCCESS RATE AS PER HISTORY OF TUBERCULOSIS

In our study we found that cornual cannulation was successful in $37.5 \%(3 / 8)$ cases who had history of tuberculosis and $77.7 \%(14 / 18)$ in patients with history of Pelvic inflammatory disease but not possible in other cases due to dense adhesions or not able to visualise cornua.

Comparison of Proximal Tubal Occlusion by HSG and Laparoscopy

HSG was done in 40 patients and it was able to diagnose 70 proximal tubal occlusion that constitutes $87.5 \%$ but on laparoscopy only 64 were confirmed which is $80 \%$ with $27.2 \%$ false positive rate of HSG as Laparoscopy is Gold standard. Also Sensitivity of HSG is found to be $86.4 \%$. (Table no.1). In 8 patients HSG could not be done due to cervical stenosis and patient noncompliance.

Table no. 1 - Comparison of Proximal Tubal Occlusion by HSG and Laparoscopy

\begin{tabular}{|l|l|l|}
\hline & Block On HSG & Block on Laparoscopy \\
\hline Proximal Tubal Occlusion & $70 / 80(87.5 \%)$ & $64 / 80(80 \%)$ \\
\hline
\end{tabular}

Success rate of Cornual Cannulation by Hysterolaparoscopy

In our study, success rate of cornual cannulation is $83.36 \%$ in unilateral cases and $76.92 \%$ in bilateral. (Table no. 2 )

Table no. 2. Success rate of Cornual Cannulation by Hysterolaparoscopy

\begin{tabular}{|l|l|l|l|}
\hline & No. of cases with Block & \multicolumn{3}{|l|}{ Success Rate of cases } \\
\cline { 3 - 4 } & on Laparoscopy & No. & $\%$ \\
\hline Unilateral & $22 / 48$ & $19 / 22$ & $83.36 \%$ \\
\hline Bilateral & $26 / 48$ & $20 / 26$ & $76.92 \%$ \\
\hline
\end{tabular}

\section{DISCUSSION}

In our institute, we studied 48 patients who underwent Hysterolaparoscopic cornual cannulation for the proximal tubal block 
and we conclude the following results. The age of the women ranged from 21 to 41 years with mean age of 30.2 years. Hysteroscopic cannulation was attempted in 74 Fallopian tubes. The success rate per tube was $79.72 \%(59 / 74)$ and per patient $81.25 \%(39 / 48)$. This results are almost similar to the results given by Sangeeta Das and et al in the tertiary referral unit at St Mary's Hospital, Manchester a total of 53 women has undergone hysteroscopic tubal cannulation and diagnostic laparoscopy. Hysteroscopic cannulation was attempted in 94 Fallopian tubes. The success rate per tube was $73.4 \%$ (69/94) and the success rate per patient was $67.9 \%(36 / 53)^{5}$. Also Puranchandra Mohapatra and et al found similar results in their studies with the success rate of $83 \%$.

In our study, $54.1 \%$ of women (26/48) had bilateral tubal blockage, and $45.8 \%(22 / 48)$ had unilateral blockage. Bilateral tubal cannulation was successful in $76.92 \%(20 / 26), 26.9 \%$ of cases were unsuccessful $(6 / 26)$. None of the patient was having complications like fallopian tube perforation or uterine perforation. In our study we found out that 18 cases $(37.5 \%)$ had proximal tubal block with history of pelvic inflammatory disease leading to adhesions contributing tubal cause for the infertility and almost $63.6 \%$ in unilateral and $87 \%$ in bilateral cases successful cornual cannulation is achieved. Also $16.7 \%$ patient had previous history of tuberculosis of lymph nodes, pulmonary Kochs, and abdominal tuberculosis and by cornual cannulation we obtained near about $50 \%$ success rate for proximal tubal patency. The patients who had previous history of genital tuberculosis, the endometrial cavity was partially or completely obliterated by adhesions of varying grade often involving the ostia. In only $50 \%$ cases it was possible to find out the ostia and negotiation of guide wire was possible leading to successful cornual cannulation. In 2 cases with extensive adhesions ostium cannot be identified and that lead to formation of false passage. Among the study, $22.9 \%$ patient having either unilateral or bilateral cornual block and had previous history of pelvic surgery in the form of check curettage and previous hystero-laparoscopy for the treatment of infertility and success rate of cornual cannulation is $75 \%$ in the form of spill present on laparoscopy after the hysteroscopic cornual cannulation. In $16.9 \%$ of patient, other causes for proximal tubal occlusion like polyp, fibroid and debris noted, in such cases identifying the cornua and passing of guide wire with catheter was feasible after removing pathology (polypectomy). In 7 cases, passing of the catheter and guide wire both required, and in these cases guide wire is passed beyond the point of occlusion shown on HSG. After removal of guidewire and passing of dye, spill was noted and cornual patency confirmed. As Hystero-laparoscopy is a gold standard procedure, false positive rate of HSG are $27.2 \%$ with sensitivity of $86.4 \%$ and specificity is $72.7 \%$ which is comparable to the meta-analysis of 20 studies carried out by P Swart and et al at University of Amsterdam in Netherland conclude that the high specificity of HSG makes it as a useful tool for diagnosis and ruling out tubal obstruction. ${ }^{7}$ Thus we conclude, Hysterolaparoscopy is far superior to HSG, as it is more accurate and therapeutic intervention is possible at the same time. But still in infertile women, where other causes are excluded and tuboperitoneal pathology is strongly suspected, HSG should be used as screening test as it has high specificity. It will be possible to prognosticate and segregate the patients who will need artificial reproductive treatment and they can be referred at the earliest, thus avoiding further emotional and financial trauma to the couples. Finally, HSG and Hysterolaparoscopy are complementary investigations for the fallopian tubes pathology. Both need to be considered to obtain a comprehensive and accurate assessment of tubal status as per our study. The real success of cornual cannulation lies in the outcome with pregnancy, ectopic pregnancy, as infertility is contributed by many other factors and proximal tubal block constitutes $20-30 \%$ of the infertility.

\section{REFERENCES}

1. Clinical Gynecologic Endocrinology and Infertility, 8th Edition Chapter no. 27.11561157.

2. World Health Organization, Progress in Reproductive Health Research. Assisted reproduction in developing countries facing up to the issues. UNDP/UNFPA/WHO/World Bank Special Programme of Research, Development and Research Training in Human Reproduction (HRP) Progress 2003; 63:1-8.

3. Kamalini D.,Theodore C.,W. Malo, et al. Hysteroscopic cannulation for proximal tubal obstruction: a change for the better?;FERTILITY AND STERILITY;American Society for Reproductive Medicine; $1995 ;$ Vol.63(5)

4. Novy MJ, Thurmond AS, Patton P et al. Diagnosis of cornual obstruction by transcervical fallopian tube cannulation. Fertil Steril. 1988;50(3):434-44.

5. Das, S., Nardo, L. G., Seif, M. W. Proximal tubal disease: the place for tubal cannulation. Reproductive BioMedicine Online,2007; 15(4), 383-388. doi:10.1016/s14726483(10)60362-8.

6. Mohapatra Purnachandra, Swain Sasmita, Pati Tapasi; Hysteroscopic Tubal Cannulation: Our Experience; JObstet Gynecol lnd 2004:54(5): 498-499.

7. Swart P, Mol BW, van der Veen F et al. The accuracy of hysterosalpingography in the diagnosis of tubal pathology: a meta-analysis. Fertil Steril. 1995;64(3):486-491. doi:10.1016/s0015-0282(16)57781-4. 